\title{
Regional Economic Resilience: Policy Experiences and Issues in Europe
}

\author{
Rüdiger Wink
}

Published online: 26 March 2014

(C) Springer-Verlag Berlin Heidelberg 2014

Crises seem to be a familiar phenomenon nowadays. Terror attacks, natural catastrophes like floods, thunderstorms, tsunamis or landslides, technological breakdowns like the Fukushima Daiichi nuclear disaster or increased awareness of the negative impact on human physical and mental health of various stress factors of modern life - in all cases, resilience as the capacity to avoid, withstand or adapt to crises has become a catchword to describe the capabilities to cope with negative shocks and adverse conditions. It comes as no surprise that resilience has also found its way into the discourse on regional economic development. The increased number of macroeconomic crises in many developed and emerging regions during the last two decades and, in particular, the "great recession" with its origin in banking failures and financial crisis has caused increasing interest in the potential causes of disparities in regions' capacities to cope with these shocks. In 2010, the Cambridge Journal of Regions, Economies and Society published a special issue on "The Resilient Region" to discuss the state of research on regional economic resilience. In 2013, Ron Martin and Peter Sunley, however, still stated in a discussion paper, which was also submitted to the Journal of Economic Geography (Martin/Sunley 2013: 3):

If we are to put the idea of resilience meaningfully to work in regional policy agendas and proacticess, then we need to have a clear definition, conceptualization and understanding of precisely what it is that we are trying to foster. We are not in that position at the moment.

Prof. Dr. R. Wink $(\bowtie)$

Fakultät Wirtschaftswissenschaften, Hochschule für Technik, Wirtschaft und Kultur Leipzig, Gustav-Freytag-Straße 42A, 04277 Leipzig, Deutschland

e-mail:wink@wiwi.htwk-leipzig.de
Accordingly, research on regional economic resilience is still in an infant stage. Nevertheless, statistical reports and policies, in particular in countries severely hit by the "great recession", already carry the label "resilience". The range of possible directions indicated by the discourse on resilience is still wide. On the one hand, new forms of civil participation are realised in regional governance with stronger communities and new, revived or adjusted forms of social and economic interaction like sharing economies or developing self-sufficient communities. On the other hand, the focus on adaptability and constant awareness of change as a means of achieving resilience is seen as an additional stressor and further step towards social and economic segmentation and disparities.

Against this background, the papers in this special issue take a look at current policies and policy debates from different perspectives and with various spatial foci. The aim is to understand: what is already happening in practice to foster regional economic resilience; what are common features in European regions despite differences in economic shocks, allocation of competencies among the spatial governmental levels and policy styles; how these observations fit to theoretical explanations; and which influence on regional economic policies might finally emerge from the focus on resilience. Several papers were developed based on research in a project funded by the European Spatial Observatory Network (ESPON) on "Economic crisis: resilience of regions (ECR 2)" illustrating the interest on the political level to look for experiences and approaches to integrate regional economic resilience as a strategic objective into regional policies on different spatial levels.

The issue opens with two conceptual papers. The first paper by Rüdiger Wink looks at current debates and open questions on regional economic resilience as a theoretical concept and strategic policy guideline. The author takes up 
an evolutionary perspective on the concept and discusses the impact of the path-dependence and multilateral governance structure of regional economic policies in Europe, as well as difficulties in applying complex indicators for the adaptability of regional economic systems in political processes. In the second paper, Gillian Bristow and Adrian Healy deliberate the role of sub-national policymakers within the process of building resilient regions. They stress three dimensions of policy action based on a concept of resilient regions as complex adaptive systems by discussing appropriate governance structures, the need for policy instruments driven by a clear vision, and suitable reactive and prospective interventions and the specificities of timing within regional economic resilience policies.

These more general contributions are followed by three papers dealing with specific features of resilience policies and discussing linkages to other concepts and elements of regional economic policies. James Simmie investigates the relevance of Joseph A. Schumpeter's argument stressing the role of innovations as drivers of regional business cycles. By analysing the long-term development of regional innovation systems in two contrasting regions in England he emphasises the close relationship between the concept of regional innovation systems and their corresponding policies with the adaptability of regional economies as preconditions for economic resilience. In their paper, Matthias Kiese and Christian Hundt examine the linkage between regional economic resilience and regional cluster policies, which became very popular during the last two decades. Based on empirical evidence from case studies in Germany, they argue that regional cluster policies can provide important contributions to regional economic policies by strengthening organising capacity in a region and by influencing a region's industrial structure along the potential trade-off between necessary specialisation to create economies of scale and locational competitiveness and diversity to reduce vulnerability to shocks. In the third paper of this section, Anne Otto, Ljubica Nedelkoska and Frank Neffke look at this potential trade-off between specialisation and diversity by proposing relatedness between industries as a potential structural solution to achieve regional economic resilience. They investigate skill-relatedness between industries, i.e. relationships between industries through demand for similar human capital, in the German federal state Saar-land. In the investigated region, skill-relatedness between traditional industrial sectors made it possible for workers to switch between industries more negatively affected by the "great recession" and less affected sectors, which increased the resilience of the regional labour market. This resilience, however, might be threatened in the future due to missing links with new emerging high-technology industries in the region.

The final paper by Iwona Sagan and Grzegorz Masik provides a regional case study from Poland to illustrate the specificities of opportunities and barriers in regional policy practice. By reflecting on the specific economic conditions in Poland during the "great recession", the place-based influences in the investigated region of Pomorskie and the limits to regional policies in a more centralised country in the European Union, they raise awareness for the need to link the conceptual debates on the "great picture" of a potential new policy paradigm of regional economic resilience to the uniqueness of actual policymaking and its effectiveness in any European region.

\section{Reference}

Martin, R.; Sunley, P. (2013): On the Notion of Regional Economic Resilience: Conceptualisation and Explanation. Utrecht. = Papers in Evolutionary Economic Geography 13-20. 